\title{
Radioaerosols and the updated EANM guideline in ventilation/perfusion imaging
}

\author{
Norman LaFrance ${ }^{1} \cdot$ France Fournier $^{2}$ (D) \\ Received: 13 March 2020 / Accepted: 26 March 2020 / Published online: 13 April 2020 \\ (C) Springer-Verlag GmbH Germany, part of Springer Nature 2020
}

\section{Dear Sir,}

We read with great interest the recently published update to the "EANM guideline for ventilation/perfusion single-photon emission computed tomography (SPECT) for diagnosis of pulmonary embolism and beyond" [1]. We applaud the EANM and the authors for the goal of providing guidelines to the nuclear medicine community with helpful information, along with offering strong clinical background, interpretation direction, and a focus on quality for patients. It is well known in the nuclear medicine community that ventilation/perfusion studies are an important tool in the diagnosis and management of pulmonary embolism (PE). Pulmonary embolism is a serious disease, which can have potentially significant consequences. The previous version of the guideline $[2,3]$, issued in 2009, has been cited by other organizations in the appropriate use of ventilation/perfusion scanning for diagnosing pulmonary embolus [4] and in policy recommendations [5]. It is this wide-spread attention to the previous version of the guideline that makes it important that this update of the guideline, which in addition to being comprehensive and addressing changes in interpretation, should be balanced. Such a comprehensive review and update is important to patients, policymakers and practitioners alike.

We are writing at this time because we believe the statement in updated guideline that for ventilation ${ }^{99 \mathrm{~m}} \mathrm{Tc}$-labeled carbon particles (Technegas ${ }^{\mathrm{TM}}$, Cyclomedica Australia PTY, Limited) or krypton $\left({ }^{81 \mathrm{~m}} \mathrm{Kr}\right)$ gas is preferred over diethylene

This article is part of the Topical Collection on Letter to the Editor

Norman LaFrance

nlafrance@jdi.jubl.com

France Fournier

ffournier@jdi.jubl.com

1 Jubilant Pharma Ltd., Yardley, PA, USA

2 Jubilant DraxImage Inc., Kirkland, QC, Canada triamine pentaacetic acid $\left({ }^{99 \mathrm{~m}} \mathrm{Tc}-\mathrm{DTPA}\right)$ in patients with COPD, which is featured in the abstract, should be reexamined and clarified to acknowledge that all three of the radiopharmaceuticals are recommended for ventilation studies in the appropriate patient or clinical setting [1]. In the body of the updated guideline, it clearly states, "Ventilation can be evaluated with the ${ }^{99 \mathrm{~m}} \mathrm{Tc}$-labelled aerosols, DTPA and Technegas ${ }^{\circledR}$, or krypton gas $\left({ }^{81 \mathrm{~m}} \mathrm{Kr}\right)$ " [1]. There is a reference cited which compares ${ }^{99 \mathrm{~m}} \mathrm{Tc}$-labeled carbon particles and ${ }^{99 \mathrm{~m}}$ Tc-DTPA in a clinical setting [6]. This reference includes two separate pa/tient groups: group (a) 35 patients in one group who were referred to evaluate clinically suspected PE (29 patients), evaluate alveolitis (3 patients), or evaluate lung function before surgery/lung transplant (3 patients); and group (b) 30 consecutive outpatients with known COPD. The results from this study have limitations that are often not thoroughly considered including that the key observation applies particularly to patients with obstructive disease, and an additional suggestion for more study in the obstructive group since some of the criteria used were developed for patient populations in whom acute PE is clinically suspected. The study showed that both ${ }^{99 \mathrm{~m}} \mathrm{Tc}$-DTPA and ${ }^{99 \mathrm{~m}} \mathrm{Tc}$-labeled carbon particles identify the presence of PE in non-obstructive disease patients when the pre-defined criteria are applied [6]. A published study, which includes a comparison between the radioactive gas $\left({ }^{81 \mathrm{~m}}\right.$ Krypton $)$ and the radioaerosol $\left({ }^{99 \mathrm{~m}} \mathrm{Tc}\right.$-DTPA $)$, reports that regional diagnostic information is similar for each radiotracer for the scintigraphic diagnosis of PE [7].

The unique value of ${ }^{99 \mathrm{~m}} \mathrm{Tc}$-DTPA in studying alveolocapillary permeability, which is not possible with ${ }^{99 \mathrm{~m}} \mathrm{Tc}$-labeled carbon particles, is acknowledged in the updated guideline. This distinct application, while being outside of the focus on PE, appears not have been fully appreciated in the recommendations and preferences regarding radiopharmaceuticals for ventilation included in the updated guideline [1]. The ongoing COVID-19 pandemic, with its significant pulmonary and alveolar membrane cellular pathology, post-infection patient evaluation of lung pathology and particularly alveolar 
membrane permeability and function abnormalities is only possible with 99mTc-DTPA's unique capability to evaluate their membrane diffusion status.

The updated guideline indicates that there is not much new in the way of technical aspects of V/P SPECT [1]. The accompanying editorial, "A guide for a brave future for lung ventilation/perfusion tomography: the most important pulmonary nuclear medicine technique" [8], also acknowledges that the technique for $\mathrm{V} / \mathrm{P}$ SPECT has remained largely stable, but notes the development of cameras and software for $\mathrm{V} / \mathrm{P}$ SPECT. Both the updated guideline and the editorial seem to overlook improvements that have evolved with nebulizers, which have produced smaller size droplets than older nebulizers. The value of using the best available nebulizer to reduce central deposition and hot spots which may limit interpretation was recognized in the previous guideline [2]. One equipment manufacturer, for example, has described a nebulizer which produces droplets with a median mass aerodynamic diameter (MMAD) as small as $0.28 \mathrm{mcm}$ [9].

Apparently not fully considered in the recommendation on radiopharmaceuticals in the updated guideline is the albeit small, lower radiation effective dose with ${ }^{99 \mathrm{~m}}$ Tc-DTPA (0.007 $\left.\mathrm{mSv} / \mathrm{MBq}\right)$ when compared to ${ }^{99 \mathrm{~m}} \mathrm{Tc}$-labeled carbon particles $(0.015 \mathrm{mSV} / \mathrm{MBq})$ [1]. The comparison study (Jogi, 2010) cited above presents the radiation dose from the ${ }^{99 \mathrm{~m}}$ Tc-DTPA $+{ }^{99 \mathrm{~m}}$ Tc-MAA study, when combined for a 1-day V/P study as $1.5 \mathrm{mSv}$ compared to a radiation dose from the ${ }^{99 \mathrm{~m}} \mathrm{Tc}$ labeled carbon particles $+{ }^{99 \mathrm{~m}} \mathrm{Tc}-\mathrm{MAA}$ study when combined for a 1-day V/P study as $1.8 \mathrm{mSv}$ [6]. The radiation exposure from either of these $\mathrm{V} / \mathrm{P}$ procedures is much lower than the radiation exposure with CTPA [1]. From the dosimetry perspective, for ${ }^{99 \mathrm{~m}} \mathrm{Tc}$-labeled carbon particles the critical organ is the lung $(0.11 \mathrm{mGy} /$ $\mathrm{MBq}$ ), while the critical organ for ${ }^{99 \mathrm{~m}} \mathrm{Tc}$-DTPA is the bladder $(0.047 \mathrm{mGy} / \mathrm{MBq})$ [1].

The biological half-life as presented in the updated guideline is different between the two radioaerosols. In the updated guideline, the reported clearance of ${ }^{99 \mathrm{~m}} \mathrm{Tc}$ DTPA is approximately 55-108 min, while the reported clearance of ${ }^{99 \mathrm{~m}} \mathrm{Tc}$-labeled carbon particles is approximately $135 \mathrm{~h}$ [1]. Some may see the shorter biological half-life as an advantage leading to faster clearance and to lower radiation exposure including to the lung, as well as providing clinical information regarding alveolo-capillary permeability, while others may see it as a potential disadvantage for obtaining certain image sets and measurements of COPD. The excretion of ${ }^{99 \mathrm{~m}} \mathrm{Tc}-\mathrm{DTPA}$ is through the kidneys, while ${ }^{99 \mathrm{~m}} \mathrm{Tc}$-labeled carbon particles are slowly cleared from the alveolar region by resorption [2].

Another difference between the two radioaerosols that may not have been fully appreciated in the recommendation is that after reconstitution, ${ }^{99 \mathrm{~m}}$ Tc-DTPA may be used for up to $12 \mathrm{~h}$ under the recommended storage conditions [10]. This characteristic permits ${ }^{99 \mathrm{~m}} \mathrm{Tc}-\mathrm{DTPA}$ to be prepared locally or to be distributed by a radiopharmacy. ${ }^{99 \mathrm{~m}} \mathrm{Tc}-$ labeled carbon particles tend to grow by aggregation and should not be used more than 10 min after generation [1]. Preparation of ${ }^{99 \mathrm{~m}} \mathrm{Tc}-$ labeled carbon particles requires an onsite generator.

The recently approved the U.S. package insert for lung ventilation imaging with ${ }^{99 \mathrm{~m}} \mathrm{Tc}-\mathrm{DTPA}$ notes, when describing Image Interpretation Risks in Lung Ventilation Studies: "In patients with obstructive pulmonary disease there may be deposition of particles in the proximal airways influencing image quality and interfering with diagnostic interpretation, therefore to ensure diagnostic quality, careful use of the nebulizer to assure optimal particle delivery is essential. If interfering particle deposition occurs, consider additional diagnostic options" [10]. According to the updated guideline, hotspots with ${ }^{99 \mathrm{~m}} \mathrm{Tc}$-labeled carbon particles are seen in some patients with severe airway obstruction [1]. Also, in describing pitfalls in image interpretation of $\mathrm{V} / \mathrm{P}_{\text {SPECT }}$, the updated guideline comments that on rare occasions in patients with emphysema ${ }^{99 \mathrm{~m}} \mathrm{Tc}$-labeled carbon particles are trapped in bullae in which perfusion is absent. This causes a pattern that may be mistaken for a mismatch [1]. Further, the updated guideline observes uneven aerosol distribution and reduced ${ }^{99 \mathrm{~m}} \mathrm{Tc}$-labeled carbon particles penetration in grade 2 COPD patients as well as impaired ${ }^{99 \mathrm{~m}} \mathrm{Tc}$-labeled carbon particles penetration to the periphery and a central deposition in large airways, usually with large areas of reduced/absent ventilation in grade 3 COPD patients [1].

The diagnostic algorithm provided in the updated guideline is a helpful tool for choosing the appropriate test selection for diagnosing or excluding PE. It does not make any distinction in the choice of between radiopharmaceuticals for ventilation [1].

One final observation regarding the updated guideline is the use of the proprietary or brand name (Technegas $\left.{ }^{\mathrm{TM}}\right)$ instead of the non-proprietary or generic name $\left({ }^{99 \mathrm{~m}} \mathrm{Tc}\right.$-labeled carbon particles) throughout the publication. This choice of nomenclature in the published updated guideline is surprising and appears counter to the instructions to authors for submitting publications to many biomedical journals, such as the New England Journal of Medicine, and the Journal of Nuclear Medicine [11, 12], which generally recommend the use of generic names. The instructions for these journals, for example, recommend that the generic name should be used throughout a publication. When a proprietary name is used, the proprietary (brand) name (including the manufacturer) generally should be mentioned only once following the first use of the generic name.

Based on the information discussed above, we would request that the authors clarify that all three of the radiopharmaceuticals for ventilation may be helpful in the 
appropriate patient when evaluating the possibility of PE and beyond.

\section{Compliance with ethical standards}

Conflict of interest The authors are employees of Jubilant Pharma and Jubilant DraxImage and declare that they have no conflict of interest.

Ethical approval This article does not contain any studies with animals or human participants performed by any of the authors.

Informed consent Not applicable.

\section{References}

1. Bajc M, Schümichen C, Grüning T, Lindqvist A, Le Roux PY, Alatri A, et al. EANM guideline for ventilation/perfusion single photon emission computed tomography (SPECT) for diagnosis of pulmonary embolism and beyond. Eur J Nucl Med Mol Imaging. 2019. https://doi.org/10.1007/s00259-019-04450-0.

2. Bajc M, Neilly JB, Miniati M, Schuemichen C, Meignan M, Jonson B. EANM guidelines for ventilation/perfusion scintigraphy: part 1. Pulmonary imaging with ventilation/perfusion single photon emission tomography. Eur J Nucl Med Mol Imaging. 2009;36:1356-70.

3. Bajc M, Neilly JB, Miniati M, Schuemichen C, Meignan M, Jonson B. EANM guidelines for ventilation/perfusion scintigraphy: part 2. Algorithms and clinical considerations for diagnosis of pulmonary emboli with V/P(SPECT) and MDCT. Eur J Nucl Med Mol Imaging. 2009;36:1528-38.

4. Waxman AD, Bajc M, Brown M, Fahey FH, Freeman LM, Haramati LB, et al. Appropriate use criteria for ventilation- perfusion imaging in pulmonary embolism: summary and excerpts. J Nucl Med. 2017;58:13N-5N.

5. Leblanc M, Tessier M, Ollenberger G, O'Brien C. CANM guidelines for ventilation/perfusion (V/P SPECT) in pulmonary embolism. Canadian Association of Nuclear Medicine. 2018; https:// canm-acmn.ca/resources/Documents/Guidelines_Resources/ MasterDocument_Final_Nov_21_incl-Exec-Sum_ver3_Dec.\% 2012_pdf. .

6. Jögi J, Jonson B, Ekberg M, Bajc M. Ventilation-perfusion SPECT with 99mTc-DTPA versus Technegas: a head-to-head study in obstructive and nonobstructive disease. J Nucl med. 2010;51:735-41.

7. Ramanna L, Alderson PO, Waxman AD, Berman DS, Brachman MB, Kroop SA, et al. regional comparison of technetium-99m DTPA aerosol and radioactive gas ventilation (xenon and krypton) studies in patients with suspected pulmonary embolism. J Nucl Med. 1986;27:1391-6.

8. Bajc M, Jonson B, Delgado Bolton RC. A guide for a brave future for lung ventilation/perfusion tomography: the most important pulmonary nuclear medicine technique. Eur J Nuc Med Mol Imaging. 2019;46:2427-8.

9. AeroVent Jr Brochure. Medi/Nuclear Corporation. 2016. http:// www.medinuclear.com/site/1927medi/AeroVent_Jr._Brochure.pdf. Accessed 14 Jan 2020.

10. DRAXIMAGE® DTPA (Kit for the preparation of Technetium Tc99m pentetate injection) [package insert]. Kirkland, Quebec, Canada. Jubilant DraxImage, Inc; 2018.

11. New Manuscripts | NEJM Author Center. In: New England Journal of Medicine. https://www.nejm.org/author-center/newmanuscripts. Accessed 15 Jan 2020.

12. The Journal of Nuclear Medicine Instructions for Authors. In: The Journal of Nuclear Medicine. http://jnm.snmjournals.org/site/misc/ JNM\%20Info\%20for\%20Authors.pdf. Accessed 15 Jan 2020.

Publisher's note Springer Nature remains neutral with regard to jurisdictional claims in published maps and institutional affiliations. 